\title{
GESTAO DOS RESIDUOS DA CONSTRUCAO CIVIL: ESTUDO DE CASO EM UBERABA
}

\author{
WASTE MANAGEMENT OF CIVIL CONSTRUCTION : A CASE STUDY IN \\ UBERABA
}

Mayara Maezano Faita, Luiz Alberto Vieira Sarmento

Universidade Tecnológica Federal do Paraná - UTFPR, Pós-Graduação: Especialização em Gestão Ambiental em Municípios, Medianeira, PR.

E-mail: mayarafaita@gmail.com1

RESUMO - Este estudo teve como temática a gestão dos resíduos da construção civil de Uberaba. O relato e avaliação da gestão quanto sua aplicabilidade e eficiência poderá ser utilizado como orientação à administração pública em questão e instrumento comparativo em municípios de características similares. O objetivo é diagnosticar o manejo dos resíduos da construção civil em Uberaba e avaliar se a gestão tem funcionado de acordo com as expectativas. O município dispõe de legislação própria e alternativas que auxiliam a população na sua destinação adequada. São disponibilizados locais de entrega voluntária (ecoponto) para volumes de até $1 \mathrm{~m}^{3}$ e caçambeiros cadastrados na prefeitura para a coleta de resíduos que excedam a quantia observada. Apesar da estrutura disponibilizada, esta forma de gestão não tem correspondido com as expectativas esperadas. A deficiência na estrutura organizacional, divulgação dos ecopontos e horários de funcionamento, tem refletido em disposição irregular de resíduos da construção civil.

Palavras-chave: Ecoponto; Resíduos de Construção; Ponto de Entrega Voluntária; Gestão Municipal; Uberaba.

Recebido em: 17/08/2015

Revisado em: 04/09/2015

Aprovado em: 09/09/2015
ABSTRACT - This study was subject to waste management of the construction of Uberaba. The reporting and evaluation of management as to its applicability and efficiency can be used as a guide to government in question and as a comparative tool for municipalities with similar characteristics. The aim is to diagnose the management of construction waste in Uberaba and evaluate whether management has worked out according to expectations. The city has its own laws and some alternatives that assist the population in its proper disposal. Local voluntary delivery (recycling center) for volumes up-to $1 \mathrm{~m}^{3}$ and registered dump cart workers at the town hall to collect waste in excess of the amount observed are available. Although the structure provided, this form of management hasn't corresponded with the expectations. The deficiency in the organizational structure, reporting 
of recycling center and the schedule of operation, has reflected in an irregular arrangement of construction waste.

Keywords: Ecopoint; Construction Waste; Point of Voluntary Delivery; Municipal Management; Uberaba. 


\section{INTRODUÇÃO}

Nos últimos anos, os municípios brasileiros vêm sofrendo alterações em suas gestões, envolvendo maior preocupação com as questões ambientais. Estas mudanças vêm partindo principalmente da consolidação das Leis Federais 11.445/07 (BRASIL, 2007) e 12.305/10 (BRASIL, 2010), que estabelecem, respectivamente, as Diretrizes Nacionais para o Saneamento Básico e a Política Nacional de Resíduos Sólidos e determinam a elaboração de Planos Municipais de Saneamento Básico e de Gestão Integrada de Resíduos Sólidos, como pré-requisito para obtenção de recursos da União.

A proposta deste estudo leva em consideração a importância da destinação adequada dos resíduos sólidos, bem como, o aumento das demandas no setor de construção civil nos últimos anos, visando analisar e relatar a situação da gestão dos resíduos da construção civil (RCC) em Uberaba.

Esta análise foi realizada, visto que foi elaborado o Plano Municipal de Saneamento Básico ${ }^{1}$ (PMSB) em Uberaba, no qual foram realizadas etapas de planejamento e visitas ao local. A participação na elaboração deste plano foi de fundamental importância para concepção deste estudo, que tratará uma

\footnotetext{
1 O autor deste trabalho participou da elaboração do Plano Municipal de Saneamento Básico como analista ambiental em conjunto com equipe técnica da empresa ganhadora da licitação.
}

abordagem específica, no que se refere à questão dos RCC.

Esta proposta, poderá ser utilizada como orientação à administração pública de Uberaba, além de servir de instrumento comparativo à gestão municipal de RCC em municípios de características similares às do município abordado, a título de informação e exemplo a ser analisado.

O objetivo deste estudo foi diagnosticar o manejo dos resíduos da construção civil no Município de Uberaba e avaliar se a gestão está de acordo com as diretrizes da Lei Municipal n¹0.876/09 (UBERABA, 2009).

\section{METODOLOGIA}

Para o desenvolvimento do presente trabalho foram realizadas as etapas a seguir: Descrição do local de pesquisa; Definição do tipo de pesquisa; Instrumentos de coletas de dados; Análise de dados.

\section{LOCAL DA PESQUISA}

O Município de Uberaba, localiza-se no Estado de Minas Gerais, na microrregião do Triângulo Mineiro, latitude Sul 19o 45' 27" e longitude Oeste 470 55' 36". Uberaba é limitada pelos seguintes municípios: ao Norte com Uberlândia e Indianópolis, Leste com Nova Ponte e Sacramento, Oeste com Conceição das Alagoas e Veríssimo e, por fim, 


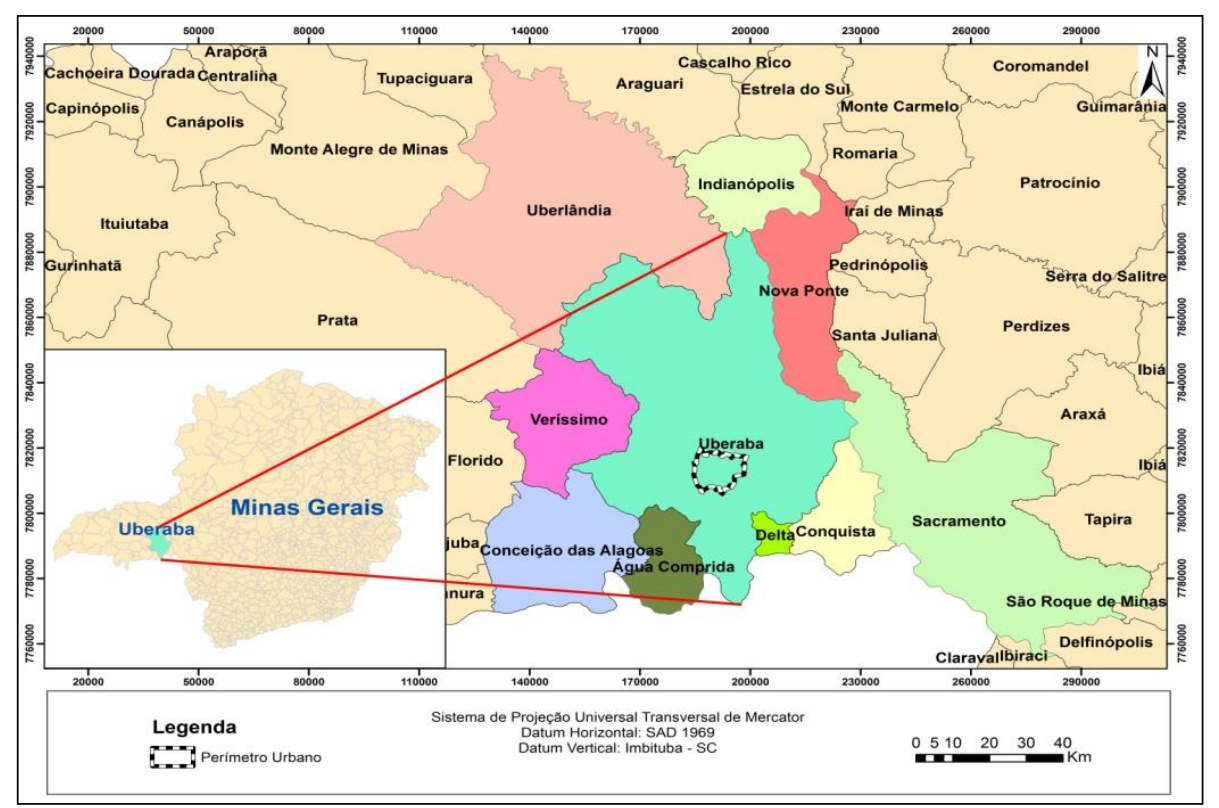

Figura 1. Localização de Uberaba e seus municípios limítrofes.

Fonte: IBGE (2012)

A área total do município é de $4.540,51 \mathrm{~km}^{2}$, dos quais $256,00 \mathrm{~km}^{2}$ são ocupados pelo perímetro urbano e $4.284,51$ $\mathrm{km}^{2}$ são áreas rurais. A altitude máxima encontrada é de $1.031 \mathrm{~m}$, na Serra de Ponte Alta, a mínima é de $522 \mathrm{~m}$ e a média $765 \mathrm{~m}$.

\section{TIPO DE PESQUISA}

O tipo de pesquisa adotado é caracterizado como estudo de caso. É um método qualitativo que consiste em aprofundamento de algo unitário, individual, e auxilia questionamentos que o pesquisador não tem controle sobre o fenômeno estudado.

Conforme Yin (2001) o estudo de caso é uma estratégia de pesquisa que compreende um método que abrange tudo em abordagens específicas de coletas e análise de dados. É um estudo empírico que busca determinar ou testar uma teoria, esclarecer decisões a serem tomadas. Os estudos de caso podem ser:

- Exploratórios: quando se quer encontrar informações preliminares sobre o assunto estudado. Uma boa abordagem é quando se utiliza de considerações opostas, em que existem diferentes perspectivas, aumentando as chances de que o estudo seja um modelo exemplar.

- Descritivos: cujo objetivo é descrever o Estudo de Caso.

- Analíticos: quando se quer problematizar ou produzir novas teorias que irão procurando problematizar o seu objeto, construir ou desenvolver novas teorias que irão ser confrontadas com as 
teorias que já existiam, proporcionando avanços do conhecimento.

No caso deste estudo, o método adotado é o estudo de caso descritivo. É uma investigação que trata sobre uma situação específica, procurando encontrar as características e o que há de essencial para o estudo.

\section{INSTRUMENTOS DE COLETA DE DADOS}

Para a consecução do estudo, foi realizado levantamento de informações fornecidas pela administração local e/ou adquiridas através de órgãos oficiais. Realizou-se visita de campo, levantamento de dados junto aos setores da administração relacionados à gestão dos RCC e levantamento fotográfico.

\section{ANÁLISE DOS DADOS}

A partir de dados coletados, conforme descritos no item 3.3. deste documento, estes serão analisados como um estudo de caso. Serão descritas de forma detalhada as características principais do município, contextualizando-o, bem como a maneira de gestão dos RCC.

\section{RESULTADOS}

Em Uberaba, conforme informado pela secretaria responsável, existem 11 ecopontos para disposição de RCC, localizados conforme Tabela 2.

Tabela 1. Bairro e endereço de cada Ecoponto em Uberaba - MG.

\begin{tabular}{ccc}
\hline ECOPONTO & BAIRRO & ENDEREÇO \\
\hline $\mathbf{1}$ & Alfredo Freire & Rua Iracema Barreto Pires, 280 \\
$\mathbf{2}$ & Amoroso Costa & Rua Eva das Graças Oliveira Silva, 552 \\
$\mathbf{3}$ & Bairro de Lourdes & Rua Ataliba Guaritá, 216 - Jd. Califórnia \\
$\mathbf{4}$ & Estados Unidos & Rua Alaska, 120 \\
$\mathbf{5}$ & Grande Horizonte & Av. Jaraguá, 810 - Residencial Serra do Sol \\
$\mathbf{6}$ & Maracanã & Rua José Tinoco, 365 \\
$\mathbf{7}$ & Morumbi & Rua Cláudio Talarico, 890 \\
$\mathbf{8}$ & Paraíso & Rua Nelson Ciabotti, 51 - Pq. São José \\
$\mathbf{9}$ & Parque das Américas & Rua Antônio Alves Fontes, 961 - Conj. Margarida Rosa Azevedo \\
$\mathbf{1 0}$ & Residencial 2000 & Rua André Luiz Samuel Alves, 170 \\
$\mathbf{1 1}$ & Valim de Melo & Rua Norma Menegaz Resende, 1.222 \\
\hline
\end{tabular}

Fonte: Uberaba. Prefeitura Municipal (2014).

A estrutura física do ecoponto é cercada e sinalizada, possui ambiente para permanência do funcionário, docas e caçambas para segregação dos resíduos sólidos, conforme Figura 2. 


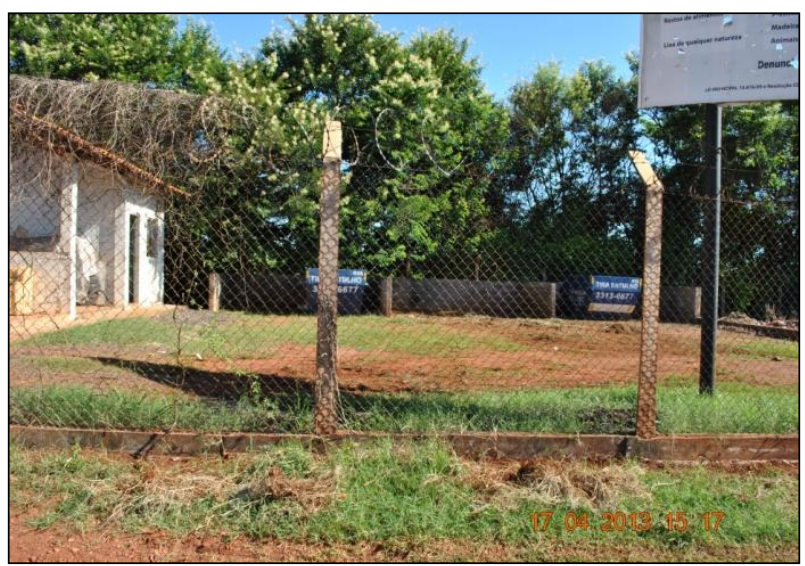

Figura 2. Estrutura física do ecoponto.

Fonte: Autor (2013)

Os tipos de resíduos permitidos e proibidos são sinalizados em placa que fica frente ao ecoponto, a fim de orientar a população quanto à destinação dos resíduos (Figura 3).

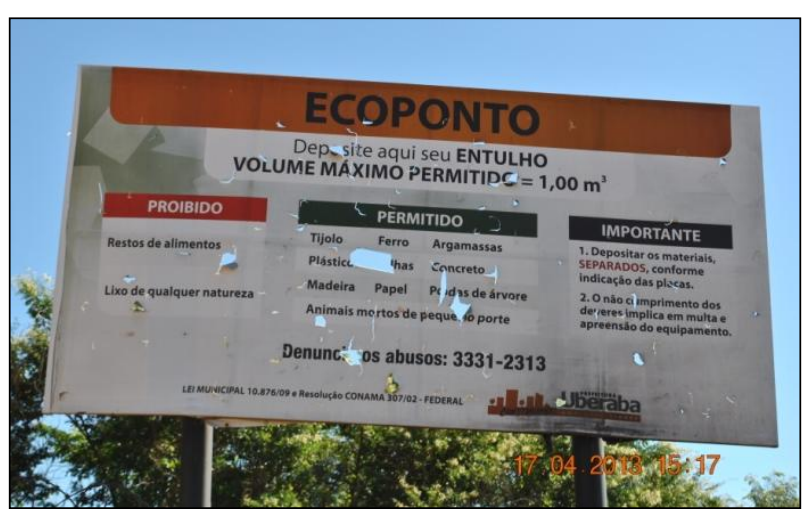

Figura 3. Sinalização dos tipos de resíduos a serem depositados.

Fonte: Autor (2013)

Nota-se que a placa de um dos ecopontos visitados encontra-se em más condições de visibilidade, dificultando o munícipe na identificação do tipo de resíduo a ser levado neste local. Para melhor entendimento, destaca-se os seguintes resíduos de entrega permitida no local:

- Tijolo;

- Ferro;

- Argamassa;
- Plásticos;

- Telhas;

- Concreto;

- Madeira;

- Papel;

- Podas de árvore;

- Animais mortos de pequeno porte.

Outro detalhe sinalizado na placa, é a necessidade de dispor os materiais de forma 
separada, conforme indicação no local, e implicância de multa no caso de não cumprimento dos deveres.

São detalhes importantes, que devem ser de conhecimento da população, porém na prática, nota-se a necessidade de manutenção da placa informativa para

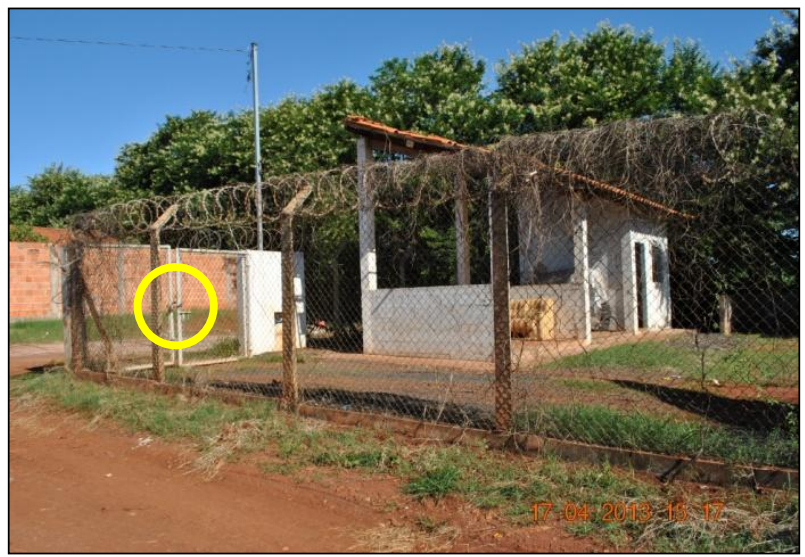

Figura 4. Ecoponto trancado.

Fonte: Autor (2013).

Desta forma a população depositava os resíduos nas proximidades do ecoponto e até mesmo frente à sua entrada (Figura 5).

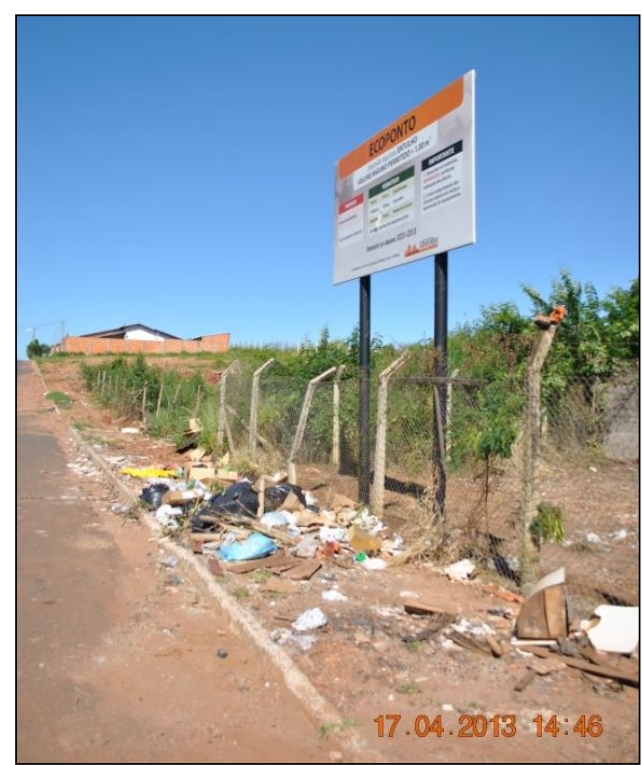

Figura 5. Disposição irregular de resíduos no entorno do ecoponto.

Fonte: Autor (2013). 
Observou-se em visita que mesmo quando o ecoponto estava em funcionamento, havia falta de atendimento de funcionários para orientação quanto à disposição dos resíduos.

\section{DISCUSSÃO}

No Município de Uberaba, formalizado com legislações específicas para resíduos sólidos e RCC, as questões de coleta, armazenamento, transporte e destinação final dos RCC se mostram consolidadas, porém na prática, não é o que se constata.

Um dos instrumentos de política pública do município, a Lei $\mathrm{n}^{\circ} 10.876$ (UBERABA, 2009), apresenta como alternativa aos pequenos geradores, a construção de pontos de coleta perenes de resíduos, denominados ecopontos, dos quais os RCC fazem parte.

Referida lei, permite a disposição de RCC de munícipes e pequenos coletores, cadastrados na Prefeitura Municipal, limitados ao volume de $1 \mathrm{~m}^{3}$, conforme $\S 1^{\circ}$ do Art. $7^{\circ}$. Nos $\S 3^{\circ}$ e $\S 4^{\circ}$ deste mesmo artigo fica estabelecido o seguinte:

\begin{tabular}{|c|}
\hline Os \\
\hline para \\
\hline $\begin{array}{l}\text { lolumes, à } \\
\text { emunerada dos remoçãc } \\
\text { ealizada pelos pequenos } \\
\text { ealizada } \\
\text { coletores privados sediados } \\
\text { los Ecopontos. }\end{array}$ \\
\hline $\begin{array}{l}4^{\circ} \text { Os Ecopontos, } \\
\text { omprometimento de }\end{array}$ \\
\hline
\end{tabular}

compartilhada por grupos locais que desenvolvam ações de coleta seletiva de lixo seco reciclável. (UBERABA, 2009)

Definido na lei municipal comentada, em seu Art. $7^{\circ}$, a localização dos ecopontos deve ser baseada, sempre que possível, em locais em que a população já tem o hábito de depositar os resíduos, ou seja, locais já degradados pela deposição irregular de resíduos.

Desta forma, a entrega dos resíduos, bem como a orientação da população é facilitada, pois ao chegar no local irregular em que o munícipe depositava seu resíduo, este, encontra um local adequado e com orientação sobre a deposição dos mesmos.

Os munícipes podem contar também, com empresas privadas de caçambeiros, cadastradas no departamento municipal de posturas, que podem coletar e transportar maiores volumes de RCC. De acordo com a prefeitura, são 1.870 caçambas de empresas cadastradas, e a disposição final destes resíduos é realizada em aterro privado, devidamente licenciado.

Os RCC dispostos nos ecopontos são coletados por empresa terceirizada da Prefeitura Municipal e encaminhados ao aterro sanitário municipal, utilizado na pavimentação das vias de acesso ao aterro. A Prefeitura também realiza a coleta diária de RCC e volumosos dispostos em locais irregulares no município. 
Constatou-se que apesar da implantação dos ecopontos atingir o objetivo de facilitar a destinação dos resíduos volumosos e de construção civil, sua estruturação deve ser reavaliada. Há a necessidade de divulgação ou ampliação de horário de funcionamento, bem como a disposição e treinamento de servidor público para atendimento aos munícipes.

Dentre as ações iniciais de melhorias das estruturas, houve relatos de técnico municipal de que está em andamento a adequação da estrutura física dos ecopontos de acordo com a NBR 15.112. Posteriormente a estruturação funcional e maior divulgação das ações devem ter maior atenção.

\section{CONCLUSÃO}

Considerando a evolução e maior atenção da legislação brasileira quanto às questões ambientais e dando enfoque aos resíduos sólidos da construção civil, percebese que Uberaba tem acompanhado esta preocupação e avançado em sua estruturação legislativa.

A Lei Federal 12.305/10 (BRASIL, 2010) responsabiliza o gerador em destinar de forma adequada os resíduos sólidos, dos quais fazem parte os RCC, neste sentido, Uberaba tem possibilitado alternativas facilitadoras de disposição destes resíduos beneficiando a população local.
A gestão municipal uberabense instalou pontos de entrega voluntária para alguns resíduos, que abrangem o RCC (Ecopontos), distribuídos pela cidade, com sinalização e à disposição dos munícipes. Ademais, a prefeitura municipal disponibiliza caçambeiros cadastrados, que podem ter o serviço solicitado, quando o volume máximo permitido de entrega no Ecoponto é ultrapassado.

Os resíduos dos Ecopontos, os resíduos coletados pelos caçambeiros e os resíduos dispostos de forma irregular são destinados em aterros de acordo com a classe pertinente. O Município pode ainda optar, caso viável, pela construção de uma Usina de Reciclagem de RCC, assim o material pode ser reaproveitado e a vida útil dos aterros estendida.

Apesar de todo esforço advindo da gestão municipal, foi constatado a ineficiência do funcionamento destes mecanismos facilitadores, decorrendo em deposição irregular de resíduos sólidos nas ruas e terrenos da cidade. Há disponibilidade de estrutura física e estrutura legal, porém a estrutura organizacional deve ser revista.

Neste sentido, conclui-se que não basta apresentar a estrutura necessária para a destinação adequada dos resíduos, deve-se ainda, programar todo arcabouço organizacional para que a estrutura possa funcionar conforme planejado. Deve-se ainda 
investir em campanhas educativas perenes para que a população se torne consciente de sua responsabilidade e habituada a estes mecanismos.

\section{REFERÊNCIAS}

BRASIL. Lei no. 11.445, de 05 de janeiro de 2007. Brasília, 05 de janeiro de 2007.

BRASIL. Lei no. 12.305, de 02 de agosto de 2010. Brasília DF, 02 de agosto de 2010.

UBERABA. Prefeitura Municipal. Lei 10.876, de 11 de dezembro de 2009. Uberaba, MG. 11 de dezembro de 2009.

UBERABA. Prefeitura Municipal. Plano Municipal de Saneamento Básico. 2014.

Disponível em:

<http://www.codau.com.br/pmsb/produtos. php>. Acesso em: 03 nov. 2014.

YIN, R. K. Estudo de caso: planejamento e métodos. 2. ed. Porto Alegre: Bookmam, 2001. 